\title{
El recurso contencioso-administrativo objetivo de lesividad
}

Justificación de este trabajo.

Hace aproximadamente un par de años vió la luz pública un trabajo nuestro titulado: "Problemas que plantea la utilización del recuiso contencioso-administrativo por las Corporaciones municipales contra sus propios acuerdos". En aquel trabajo, publicado antes de la promulgación de la Ley de Régimen local de 16 de diciembre de 1950, es decir, bajo la vigencia de la Ley de 1935, defendimos la posibilidad jurídica del recurso de lesividad objetivo. Nada decía la legislación española acerca de este recurso, cosa explicable, ya que el recurso de lesividad se regulaba en lit Ley general de lo Contencioso de 22 de junio de 1894, que desconoce el recurso contencioso-objetivo, mientras que el recurso contencioso objetivo se configuraba en la legislación local que no se refería para nada al recurso de lesividad.

Por otra parte, la jurisprudencia del Tribunal Supremo era reiterada en lo referente a que las Corporaciones municipales, cuando ejercían el recurso de lesividad, no ejercían acciones contenidas en la legislación municipai, sino que ejercitaban las acciones de la Ley de 1894. La doctrina española no había estudiado la posibilidad del recurso contenciosomobjetivo de lesividad, si bien López Rodó había negado la posibilidad de dicho recurso al decir: "Podría plantearse la cuestión, dice, de si la misma autoridad que dictó el acuerdo puede impugnarlo mediante el recurso de anulación. Creemos debe estimarse resuelta negativamente 
por el hecho de no concederse a la Administración otro nuedio para acudir al proceso contencioso que la previa declaración de lesividad. De lo contrário podría oponérsele el principio de que a nadie le es lícito volver contra sus propios actos, cuya única excepción se da a consecuencia de haberlos declarado lesivos." La casi segura imposibilidad de que la doctrina extranjera hubiera estudiado el problema resultaba del hecho de que el recurso de lesividad es una creación exclusiva de nuestro sistema contenciosoadministrativo.

A los dos años de haberse publicado nuestro trabajo nos parece oportuno volver a la cuestión, puesto que se han producido acontecimientos que bien pueden considerarse trascendentales para el problema. El primero de todos y el más principal de ellos es la promulgación de la Ley articulada de Régimen local de 16 de diciembre de 1950, que consagra expresamente por vez primera en España la posibilidad del recurso contencioso-abjetivo de lesividad que nosotros habíamos defendido en nuestro citado trabajo, y que no figuraba en la Ley de Bases de 1945. El segundo de ellos es la aparición del texto refundido de la Ley de la Jurisdicción contencioso-administrativa, en el que se conjuntan en un solo texto los preceptos relativos al recurso contra la Administración central y los que hacen referencia a la impugnación contenciosa de las Corporaciones locales. El tercero, finalmente, en la aparición del juicio y crítica que mereciera a algunos el recurso objetivo de lesividad propugnado por nosotros, y que constituye ya Derecho positivo expreso en la esfera local desde la vigencia del nuevo ordenamiento municipal y provincial.

Planteamiento de la cuestión a que hace referencia el recurso contencioso-objetivo de lesividad.

Los supuestos a que hace referencia el recurso san los siguientes: 1. Una resolución emanada de las Corporaciones locales que sea declaratoria de derechos para un particular. 2. $Q$ Que dicha resolución sea ilegal y al mismo tiempo lesione económicamente a la Corporación que lo adoptó. 3. Que la resolución impugna- 
ble no lesione un derecho subjetivo de la Corporación, pero que si lesione un interés directo de la misma.

El primer requisito es necesario y específico, porque si el acuerdo no fuese declaratorio de derechos a favor de tercero, la Administración podría volver sobre su acuerdo en virtud del principio de la revocación de los actos administrativos.

El segundo es asimismo necesario para la configuración del recurso, ya que la lesividad en la nueva Ley ha de referirse a $i r_{1}$ tereses económicos, y por otra parte la ilegalidad del acuerdo ce hace necesaria como un requisito para que el recurso sea objetivo.

Finalmente, el tercer supuesto es también necesario, puesto que si la ilegalidad del acuerdo determinara conjuntamente una vulneración de un derecho subjetivo de la Corporación, estaría. mos en presencia de un recurso de plena jurisdicción. Se necesita que la legalidad vulnerada protegiese indirectamente una situación subjetiva de la Corporación, un interés de la misma, para que. quede configurado el recurso como un contenciosa-objetivo.

Necesidad y utilidad del nuevo recurso.

Fácilmente se deduce que la admisión del recurso de lesividad objetivo supone la mejor fórmula en que pueden aunarse una auténtica necesidad para la Administración a la par que una plena garantía jurisdiccional para los derechos subjetivos de los particulares reconocidos en la resolución impugnable.

En efecto, de no ser así habría que llegar a una de las siguientes hipótesis. La Administración en aquellos casos en que hubiera dictado una resolución declaratoria de derechos, pero que fuera ilegal y lesionase no sus derechos subjetivos, sino sólo sus intereses legítimos, no podría impugnar en vía contenciosa sus propias decisiones, porque no podría invocar la lesión en el derecho subjetivo, requisito éste exigido para que prospere el recurso de lesividad subjetivo. Sin embargo, es cierto que han prosperado al amparo de la Ley de 22 de junio de 1894 acciones de lesividad sin lesión de derecho subjetivo. Pero esto no es más que un aspecto de otra cuestión. cual es el cierto carácter objetivo que la 
Jurisprudencia del Tribunal Supremo viene dando al contencioso de la Ley de 1894, aspecto éste estudiado por Ballbé, Martínez Useros, Garrido Falla, Leira Cobeña, Serrano Guirado y Enterría Carande, y que ha llegado incluso al recurso de lesividad.

De no admitirse, pues, el recurso de lesividad objetivo, no habría medio legal para la Administración de impugnar sus pro pias decisiones, aun siendo ilegales y perjudiciales para sus intereses. Tendría que llegarse a otra fórmula tan extremista como injusta, cual sería admitir en tales casos la posibilidad de que la Administración revocase su resolución, aun cuando fuese declaratoria de derechos, lo que no dejaría de ir en contra del principio de la irrevocabilidad de los.actos administrativos declaratorios die derechos subjetivos. Era la fórmula del Derecho rumano expuesta por Constantin $G$. Rarincesco al manifestar la posibilidad de que tanto los actos subjetivos como los actos condición podían ser revocados, aun cuando de ellos nacieran derechos subjetivos o situaciones jurídicas individuales.

A nuestro juicio, pues, hay que buscar una fórmula que aúne la necesidad de la Administración de que no subsistan actos ilegales que perjudican sus intereses con la garantía de los particulares que adquirieron derechos subjetivos como consecuencia de dichas resoluciones. Hay que examinar, pues, si el acto es o no ilegal, si los derechos que en él tuvieron consagración están también afectados de ilegalidad $y$, finalmente, si la Corporación que dictó el acuerdo se ve lesionada en sus intereses. Realizar todo esto es una auténtica función jurisdiccional, en la que se da garantía al particular afectado, puesto que van a ser los tribunales independientes los que van a conocer la cuestión, y a la Administración se le da la posibilidad, al convertirla en recurtente, de que ataque aquellos actos que por estimarlos ilegales no deben subsistir. El recurso contencioso-objetivo de lesividad es la' única vía idónea para ello.

Consagración legal del recurso contencioso-objetivo de lesicidad.

El artículo 391 de la Ley de Régimen local de 16 de diciembre de 1950 consagra expresamente por vez primera en nuestra patria 
la nueva modalidad a que dedicamos nuestra atención. "Las Autoridades y Corporaciones locales, dice, podrán interponer ante el Tribunal provincial de lo Contencioso recurso contra sus propias decisiones, previa la correspondiente de lesividad para los intereses económicos de la Corporación local respectiva, siempre que dichas decisiones impliquen, además, vulneración de un derecho administrativo de la referida Corporación o violación de leyes o disposiciones administrativas que motive recurso de anulación.."

El nuevo texto refundido de la Ley de lo Contencioso de 6 de febrero de 1952, en su artículo $2 .^{\circ}$, contiene el mismo precepto en relación con las Corporaciones locales.

Fácil resulta deducir, pues, que el recurso de lesividad de las Corporaciones locales es de dos clases: subjetivo, cuando además de la lesión en los intereses económicos exista vulneración de un derecho administrativo subjetivo de la Corporación, u objetivo, cuando, además de aquella lesión, exista violación de leyes o disposiciones administrativas que motive recurso de anulación.

Según la legislación vigente, hay pues que distinguir el recurso de lesividad ejercitado por la. Administración central, que a nuestro juicio legalmente será siempre subjetivo, y el recurso de lesividad ejercitado por las Corporaciones locales, que puede ser subjetivo y objetivo. De esta manera y por compensación, resulta que si bien las Corporaciones locales ven su actividad fiscalizada más ampliamente que la Administración central, porque contra sus resoluciones cabe el recurso objetivo, también cuando ellas se convierten en recurrentes contra sus propias decisiones, tienen, al menos legalmente, medios más amplios que los que la Administración central tiene cuando recurre contra sus propios actos.

Principales objeciones formuladas frente a nuestra tesis.

La configuración que hicimos del recurso objetivo de lesividad ha merecido la atención de la dọctrina que siempre, desde un plano objetivo y científico, se mostró a veces en pro y a veces en contra 
de la posibilidad por nosotros estudiada y recogida por la Ley de Régimen local. En el mismo tono objetivo y científico queremos nosotros ahora intentar rechazar algunas de las objeciones que a nuestra tesis le han sido formuladas:

1. Tal recurso supone amparar más los intereses que los derechos subjetivos.

González Pérez, en la recensión hecha a nuestro trabajo en el número 4 de la Revista de Administración Pública, se expresaba en contra de nuestra tesis con las siguientes palabras: "No obstante estimamos-y de aquí que sea censurable el criterio de la Ley de Régimen local en este punto concreto-que la más correcta es la opinión contraria. No hemos de olvidar que el proceso de lesividad entra en juego allí donde la Administración no puede revocar -un acto de la misma, lo que no puede hacer cuando es declaratorio de derechos. Luego supone la excepción a un principio general-que nadie puede ir válidamente contra sus propios actos-y la lesión de unos derechos adquiridos por el particular: de aquí, la reiterada jurisprudencia que exige que ello sea posible cuando el acto lesione derechos subjetivos de la Administración, más dignos de respeto que los del particular; pero sería absurdo revocar el acto que creó derechos en favor del particular, porque lesione un mero interés de la Administración. Sólo en la pugna de los derechos puede admitirse que prevalezca el de la Administración; pero nunca en la pugna de un derecho subjetivo y un interés, aunque el acto que reconoció aquél esté viciado."

A nuestro juicio, tal objeción no desvirtúa la posibilidad del recurso objetivo de lesividad, ya que estimamos que si el derecho subjetivo otorgado a un particular por un acto administrativo está en contradicción con el derecho objetivo, y ese derecho objetivo conculcado reconoce intereses legitimos a la Administración, en modo alguno pueden prevalecer frente a tales intereses legítimos unos derechos subjetivos ilegítimos, y no pueden prevalecer porque no caben derechos subjetivos nacidos en flagrante contradicción con el derecho objetivo: 
Lo que a nuestra manera de ver resulta incomprensible es negar ia posibilidad de impugnación objetiva frente a unos actos ilegales que han concedido derechos subjetivos ilegales y que han menoscabado los intereses económicos de la Administración a la par que sus auténticos intereses legítimos amparados por el derecho objetivo.

Pero es que aún hay más. Admitir la objeción hecha frento a nuestra tesis supone también casi la desaparición del recurso contencioso-objetivo ejercitado por los particulares frente a la Administración. Imaginemos un acto de una Corporación que reconoce derechos a un administrado, pero que el acto resulta ilegal. Imaginemos que dicho acto lesiona intereses legítimos de otro administrado distinto. Si se admite el contenido de la objeción, tendríamos que llegar al absurdo de negarle al administrado que ve lesionado sus intereses por un acto ilegal la posibilidad reconocida en nuestro Derecho municipal desde el año 1924 de utilizar la vía contencioso-objetiva, y ello porque según esta objeción merece más protección un derecho subjetivo ilegal que un auténtico interés reconocido por el derecho objetivo.

Por todo lo dicho frente a la objeción que comentamos, mantenemos nuestra tesis formulada hace dos años y confirmadł por la Ley de Régimen local en favor de la posibilidad jurídica del recurso objetivo de lesividad.

Con posterioridad, el mismo autor ha insistido en su punto de vista en su trabajo "La justicia administrativa", publicado en la Revista de Administración Puiblica, número 6, y ha abundado en otros criterios. Así se dice que el proceso de lesividad supone la excepción a un principio general, que nadie puede ir válidamente contra sus propios actos. Que mientras al particular no le es lícito en ningún caso volver contra sus propios acuerdos, la Administración puede hacerlo a través del proceso excepcional y privilegi,ıdo del recurso de lesividad subjetivo, el cual, en virtud de su carácter privilegiado y excepcional, debe interpretarse restrictivamente y no ampliar su esfera hasta convertirlo en recurso objetivo.

También discrepamos de estas afirmaciones, ya que el prin- 
cipio de que la Administración "puede volver sobre sus propios acuerdos" no es un principio excepcional, sino normal. En efecto, el principio general es de que la Administración puede revocar y volver sobre sus propios acuerdos (principio de la revocación de los actos administrativos: los actos administrativos, a diferencia de los judiciales, pueden ser revocados por la propia Administración). Excepción a este principio es el de que la Administración no puede revocar ni volver contra sus propios acuerdos declaratorios de derechos. Excepción a la excepción y, por tanto, confirmación de la regla general es el recurso de lesividad, en el que la Administración vuelve sobre sus propios actos aun siendo declaratorios de derechos, cuando tales acuerdos son ilegales. Vemos, pues, cómo no puede prevalecer el criterio de interpretación restrictiva en cuanio que el proceso de lesividad no es excepción de una norma general, sino excepción de la excepción de la regla gentral y, por tanto, un supuesto mismo de dicha regla. Por otra parte, el carácter privilegiado que se señala como propio del recurso de lesividad, en cuanto que el particular no puede recurrir contra sus propios acuerdos, es a estos efectos irrelevante, ya que los actos de los administrados no son susceptibles de recurso y sí los de la Administración. En vía contenciosa los actos de los particulares no son impugnables, y es por eso por lo que los particulares no pueden utilizar el recurso de lesividad.

2. El recurso objetivo de lesividad no puede existir porque los intereses públicos son protegidos siempre en forma directa $y$ no en forma indirecta.

Una objeción de aparente importancia es la que se configura al decir que el recurso objetivo tiene por finalidad la defensa del derecho objetivo, pero que supone también la protección de situaciones subjetivas indirectas, esto es, de intereses legítimos. Que en dicho sentido el recurso contencioso-objetivo se da sólo para los particulares, que son quienes pueden tener situaciones o intereses protegidos indirectamente, pero no para la Administración, ya que las situaciones subjetivas de ésta $o$ intereses públicos es- 
tán protegidos en forma directa, es decir, dando lugar a derechos subjetivos y no a intereses legítimos. Que podrá hablarse de intereses particulares legítimos, esto es, protegidos indirectamente, pero no de intereses públicos protegidos en forma indirecta.

Se piensa que el concepto de interés legítimo es el resultado reflejo e indirecto de una protección directa del interés público de la Administración. Que de esta protección directa del interés público resultan a veces protegidas indirectamente ciertas situaciones subjetivas de los particulares que merecen el concepto de interés legítimo. Que los intereses de la Administración se protegen siempre directa y reflexivamente, por lo que tal protección dará lugar siempre a derechos subjetivos en favor de la Administración, pero nunca a intereses legítimos. De esta forma se concluye que mal podrá thablarse de un recurso objetivo en favor de la Administración en la que ésta no puede invocar un interés legítimo sino un derecho subjetivo.

A nuestro juicio, las situaciones subjetivas de la Administración pueden protegerse indirectamente consagrándose en tales casos como auténticos intereses legítimos. Ciertamente que por lo común en la legislación administrativa de un ramo concreto se protegerán las situaciones de la Administración y sus posibilidades de actuar en esa materia de una manera directa, dando lugar a derechos subjetivos, pero al mismo tiempo han podido indirectamente resultar amparados intereses de la Administración que no habrán sido previstos reflexivamente por aquella rama de legislación. Un ejemplo pondrá más claro nuestro pensamiento. Imaginemos unas Ordenanzas municipales de construcción, una de cuyas normas, para proteger el interés público de ornato de la ciudad prohibe construir edificios en determinadas calles más allá de cierta altura. No obstante ello, la Corporación acuerda conceder licencia para construir más allá de la altura establecida en las Ordenanzas. Iuego advierte la Corporación que junto al edificin a construir está el laboratorio municipal, y que si el edificio contiguo se eleva a tal altura, el laboratorio perderá luz y resultará inservible para ciertos efectos de investigación, a no ser que el Municipio realice obras en proporción cuantiosa. Tenemos, pues. 
que la referida norma que protegió directamente el interés público de ornato, habrá protegido indirectamente otro interés de la Administración, cual era el sanitario al que se dedicaba el referido laboratorio municipal. Ciertamente que en tal caso la Corporación podría acudir al recurso de lesividad subjetivo, invocando la protección directa que a tal interés le había dispensado el derecho objetivo y no al recurso de lesividad objetivo, invocando el interés sanitario protegido indirectamente; pero si la razón que realmente impulsaba a la Corporación era la defensa del laboratorio y no el interés de ornato, tal vez estuviésemos autorizados a pensar que el acuerdo adoptado para recurrir en vía contenciosa estaba viciado en cierta forma de desviación de poder en cuanto que la finalidad que movió a la Administración para actuar no fué la que inspiraba a las Ordenanzas de construcción.

Con todo, lo fundamental es que queda demostrado prácticamente la posibilidad de que la Administración sea titular de intereses legítimos. Además, fácilmente puede pensarse que la lesión de dicho interés de la Administración no siempre coincide con la lesión de derechos subjetivos de la misma, ya que el interés protegido directamente podía pertenecer a una entidad administrativa distinta de la que devenga titular de la situación subjetiva protegida indirectamente.

Por todo ello, pues, al admitirse la posibilidad de que la Administración pueda invocar intereses legítimos ante los órganos del poder judicial, es por lo que mantenemos la legitimación activa de aquélla para interponer el recurso objetivo de lesividad.

\section{3.* El recurso de lesividad es siempre objetivo.}

E] profesor Alvarez Gendín, en sus "Comentarios a la Nueva Ley de Régimen Local", publicada por la Revista DE Estudios DE LA VIDA LOCAI, aun cuando se muestra partidario de nuestra tesis del recurso de lesividad objetivo, hace algunas afirmaciones de las que, con los debidos respetos, discrepamos. En efecto, se dice: "Nosotros entendimos siempre que era la lesión al derecho objetivo la que debía acompañar al interés, para servir de base 
a la interposición del recurso de lesividad, y ello se explica, pues las Corporaciones, como no sea contractualmente. no adquieren derechos subjetivos respecto a tercero; son competencias derivadas de la ley. Por tanto, apenas se darían casos de lesividad sustentando el criterio restrictivo..." "Si bien el artículo $10^{\circ}$ de la Ley de lo Contencioso-administrativo, al contornear el recurso, se refiere a la Administración o a los particulares, y el tercer requisito para interponerlo es la vulneración de un derecho administrativo establecido anteriormente en favor del demandante por una ley, un reglamento u otro precepto administrativo, alude, sin duda, a la facultad de recurrir una Administración contra un acto de otra Administración en cualquiera de sus tres grados."

Parece, pues, desprenderse de estas palabras que el recurso de lesividad ha sido siempre o casi siempre objetivo. Para ello parece que se argumenta tanto desde un punto de vista doctrinal como desde un punto de vista legal. El primero de estos argumentos es el de que las Corporaciones locales, como no sea contractualmente, no adquieren derechos subjetivos respecto a tercero; son sólo competencias derivadas de la ley. A nuestro juicio el concepto de competencia, tan fecundo en el Derecho público, no es incompatible ni mucho menos borra al de derecho público subjetivo de la Administración. No son sólo los contratos las fuentes de derechos subjetivos para la Administración, sino que también lo es la ley. La ley fija no sólo la competẹncia de los órganos de la Administración, sino que también la configura titular de derechos públicos subjetivos frente a los particulares. Así, cuando una ley determina las atribuciones de los órganos que han de recaudar los impuestos, estamos en presencia de una norma de organización que fija las competencias de los órganos públicos; pero cuando las normas determinan y regulan la cuantía de los impuestos, no sólo fija un deber para el administrado, sino que confiere a la Administración el derẹcho público subjetivo correspondiente. En este sentido estamos plenamente de acuerdo con Garrido Falla, cuando en su interesante trabajo "La Administración y la Ley", señala que las llamadas normas de relación distribu- 
yen las esferas jurídicas de la Administración y del individuo delimitando sus respectivos derechos subjetivos.

El segundo argumento empleado parece hacer referencia a que el artículo $1 .^{\circ}$ de la Ley de lo Contencioso que exige la lesión del derecho del recurrente se refiere a la Administración, pero sólo cuando recurre frente a los actos de otra Administración. A nuestro juicio, el artículo $10^{\circ}$ de la Ley antes citada se refiere no sólo al recurso que una Administración puede-interponer frente a otra, sino también al recurso que la Administración interpone frente a sus propios acuerdos, esto es, ai recurso de lesividad. Ya Caballero Montes tuvo que salir al paso de la crítica que algunos hicieron a la Ley, señalándole el diferente trato que ésta tenía para los particulares, exigiéndoles lesión de derecho subjetivo para recurrir y para la Administración cuando recurría contra sus propios acuerdos, que no se le exigía tal invocación, por lo que el recurso podría concebirse como objetivo. Caballero Montes señalaba cómo no había pugna alguna entre los artículos $10^{\circ}$ y $7 .^{\circ}$ de la Ley. Cuando la Administración interpone el recurso de lesividad, rige para ella el artículo $1^{\circ}$, salvo el requisito primero, añadiríamos nosotros, que en tales casos se complementa con el $7 .^{\circ}$ de la Ley.

Por otra parte, el artículo $1 .^{\circ}$, al referirse al recurso contencioso, dice que lo podrá interponer el particular y la Administración sin hacer distinción ninguna, y donde la Ley no distingue no se debe distinguir. Finalmente, el artículo $2 .^{\circ}$ de la Ley de lo Contencioso, en donde se habla expresamente del recurso de lesividad, no es más que un desenvolvimiento del artículo $1 .^{\circ}$ de la misma Ley, que desarrolla los supuestos en él contenidos.

Ciertamente que hay que reconocer, como en otra parte de este estudio hemos señalado, que han prosperado recursos de lesividad interpuestos por la Administración central, en los que mal podrfa verse el agravio del derecho subjetivo de aquélla. Pero ello no puede nunca interpretarse en el sentido de que el recurso de lesividad de la Ley de lo Contencioso sea un recurso objetivo, sino como un aspecto del problema de la creación jurisprudencial por nuestro Tribunal Supremo de un recurso contencioso-objetivo de 
tipo pretorio contra las resoluciones de la Administración central por vicios de forma y de competencia.

Nuestro punto de vista en esta cuestión es el siguiente. Cabe teóricamente la posibilidad del recurso de lesividad objetivo, ya que la Administración puede ser titular de derechos públicos subjetivos nacidos al margen de todo contrato. El recurso de lesividad configurado en la Ley de 1894 es de carácter subjetivo.

4." El. recurso de lesividad no es nunca objelivo, porque en él se ventilan derechos subjetivos.

Otra objeción que pudiera oponerse a nuestra tesis es la que hace referencia a que todo recurso de lesividad por hipótesis hace referencia a los derechos subjetivos declarados en el acto que se impugna, ya que si no hubiera declaración de derechos, la Administración podría por sí misma revocar su acuerdo. El proceso en el que se ventilan derechos subjetivos de los administrados no puede ser objetivo.

A nuestro juicio tal objęción no desvirtúa en nuestro ordenamiento positivo la naturaleza objetiva del recurso de lesividad que estudiamos. En primer lugar, porque de admitir tal tesis habría que calificar como subjetivos a todos aquellos recursos interpuestos por interesados legítimos contra resoluciones de las Corporaciones locales que hubiesen. declarado derechos a favor de otros administrados. Sin entrar en las posibles diferencias doctrinales entre un proceso de anulación y un proceso objetivo, podemos afirmar que en nuestro ordenamiento positivo la naturaleza objetiva de un recurso viene dada fundamentalmente por el fin que es la defensa de la legalidad; por la legitimación del recurrente, que viene dada por la titularidad de un interés $\mathrm{y}$, finalmente, por las posibilidades de anulación y la producción de efectos uerga omnes" de la sentencia. Creemos que dichos caracteres se dan en el recurso de lesividad que estudiamos. En primer lugar, la finalidad del mismo es proteger la legalidad frente a un acto declaratorio de derechos que es ilegal. En segundo lugar, se exige para la legitimación de la Corporación provincial o municipal la tenencia 
de un interés directo en el asunto $y$, finalmente, la sentencia que ponga fin al proceso, no sólo producirá efectos por el que devino titular del derecho subjetivo declarado en el acto impugnado, sino para todos los que se vieran afectados por él.

5." La Administración tiene derecho subjetivo a la legalidad, de donde el recurso contencioso de lesividad serd siempre subjetivo.

De la misma forma como Bonnard construyó el derecho a la legalidad por parte de los administrados, lo que determinaba la naturaleza subjetiva de toda impugnación contenciosa en cuanto que la mera violación de la legalidad implicaba automáticamente la lesión del derecho subjetivo a la legalidad, otros autores como Sarwey en Alemania y Martínez Useros en España, se muestran partidarios de que la lesión del derecho objetivo del Estado determina automáticamente una lesión de su derecho subjetivo, lo que implicaría que todo recurso contencioso interpuesto por la Administración serla siempre subjetivo.

"Esa necesaria subjetivación de la infracción de la norma objetiva, escribe Martínez Useros, en su interesante trabajo "Revisibilidad de las resoluciones sobre personal", sólo se produce con respecto a uno de los elementos de la relación jurídico-pública : con respecto al Estado, o entidades que con análogo carácter soberano $\in$ n ella intervienen, por cuanto en uno $u$ Jtras se da la única posible subjetivación de los intereses colectivos (in genere». Con acierto escribio Sarwey, que aunque no exista un derecho particular lesionado, ni se ha inferido un agravio al orden jurídico general, existe un derecho subjetivo que también recibe en si la injuria : ese derecho es del Estado, que posee un especifico inverés en que no se perciba su vida ordenada."

A nuestro juicio y prescindiendo de la cuestión del derecho sub. jetivo a la legalidad por parte del Estado, concretando nuestra solución a las Corporaciones locales, creémos que éstas no tienen derecho a la legalidad y que la lesión del derecho objetivo no produce automáticamente lesión para su derecho subjetivo. En pri- 
mer lugar, porque no todo el derecho vigente en un país emana de las Corporaciones locales, sino que la mayoría emana del Estado y afecta a intereses que no son ni de la Provincia ni del Mu nicipio, siendo absurdo pensar que la lesión de dichas normas determinara una lesión del derecho subjetivo a la legalidad de todas las provincias $y$ municipios. En segundo lugar, porque el propio concepto del derecho subjetivo, como situación de poder concreta, excluye el concepto de derecho subjetivo a la legalidad desde el momento mismo en que la idea abstracta de derecho a las formas, a la competencia, etc., choca con esa posibilidad de actuación concreta que caracteriza al derecho subjetivo: Creemos que tan lejos como el administrado se encuentran las Corporaciones locales en relación con el pretendido derecho a la legalidad.

Otros problemas en torno al recurso objetivo de lesividad.

La nueva modalidad consagrada expresamente por la Ley de Régimen local y el texto refundido de la Ley de la Jurisdioción contencioso-administrativa, presenta, a nuestro juicio, problemas de interés práctico que than de plantearse en la vida jurisdiccional y administrativa en el momento mismo en que empiece a utilizarse por nuestras Corporaciones locales este nuevo tipo de pretensión.

\section{El procedimiento.}

Uno de ellos y de capital importancia por todas las consecuencias prácticas que lleva consigo, es el de cuál ha de ser el procedimiento por el que se ha de tramitar el recurso objetivo de lesividad. Según la jurisprudencia anterior a la Ley de Régimen local, los recursos que las Corporaciones interponen contra sus propios acuerdos, no son los de Ley municipal, sino los procedentes contra declaraciones lesivas según la Ley de lo Contencioso. La sentencia de 15 de noviembre de 1941 establece que el recurso de lesividad no es de los regulados en el artículo 253 del Estatuto municipal, sino de los comprendidos en la Ley de lo Contencioso. Según Royo Villanova, en su conocida obra Problemas de Régimen 
Juridico Municipal (Premio Nacional Calvo Sotelo, 1943), el recurso interpuesto por el Ayuntamiento contra sus propios acuerdos tiene una tramitación especial distinta de la que siguen los recursos presentados por los particulares. Esta acción es la autorizada en los artículos 2 y 7 de la Ley de 22 de junio de 1894, en relación con el artículo 15 del Reglamento.

Cuando escribimos estas líneas se han sucedido dos acontecimientos de gran trascendencia en relación con este problema. E1 primero de ellos, la promulgación del texto articulado de la Ley de Régimen local, que por vez primera consigna expresamente el recurso de lesividad objetivo. Cae por tierra la tesis clásica, según la cual, las Corporaciones locales al utilizar las acciones de lesividad, utilizaban las de la Ley de lo Contencioso y cae por tierra, porque la Ley de 22 de junio de 1894 no regula ninguna acción de naturaleza objetiva, como es la que utilizan las Corporaciones en estos casos.

Como el proceso de lesividad no era de los regulados en la Ley municipal en virtud del carácter supletorio de la Ley de lo Contencioso, se aplicaba el proceso de lesividad regulado en aquella Ley y no el de la legislación municipal. También en esta materia se ha operado una innovación de no poco interés, cual es la promulgación del texto refundido de la Ley de lo Contencioso, en la que se recogen todos los preceptos referentes a esta jurisdicción, tanto contra las resoluciones de la Administración central como en la local. Una interesante cuestión a este respecto se plantea en torno a si las normas referentes al contencioso local han perdido el carácter de normas especiales, cuyas deficiencias hubieran de suplirse por los preceptos de otro texto formal, como ocurría cuando se configuraban en la Ley de Régimen local, cuyo artículo 400 determinaba que en lo que no se hallare previsto en los artículos anteriores de la referida Ley, se aplicaría la legislación vigente de la Jurisdicción contencioso-administrativa. Al configurarse hoy en un solo texto todos los preceptos relativos a lo contencioso, no puede caber duda que el principio de supletoriedad se presenta con caracteres dudosos.

Nuestra opinión es la de que el proceso por el que ha de trami- 
tarse el recurso de lesividad objetivo, es el regulado en el texio refundido de 1952, bajo la rúbrica "Recursos contra acuerdos de las Autoridades y Corporaciones locales". Ahora bien, como en tal proceso no se configura a la Administración como demandante, habrá que aplicarles las normas específicas de lesividad reguladas en el procedimiento en única instancia ante el Tribunal Supremo. Ahora bien, tal aplicación habrá de hacerse de acuerdo con los principios que orientan el proceso correspondiente a la impugnación contra las resoluciones de las Corporaciones locales. Así por ejemplo, el artículo 35, que hace referencia a la innecesariedad del escrito de interposición cuando es la Administración demandante, determina que, en tales casos, el Fiscal presentará la demanda acompañando el expediente gubernativo. Creemos que cuando se trate de las Corporaciones locales, el Fiscal no presentará la demanda en el caso del recurso objetivo de lesividad, puesto que en el recurso objetivo el principio de la Ley es que el Fiscal actúe exclusivamente como defensor de la Ley y no como parte en el proceso.

\section{Las excepciones.}

Admitiendo pues, nuestra tesis, llegamos a la conclusión de que cuando las Corporaciones son demandantes contra sus propios acuerdos, las excepciones tendrán siempre el carácter de perentorias, con lo cual ponemos a las Corporaciones en igualdad de trato con los particulares. De admitirse que el proceso no es el que nosotros defendemos, se llegaría al absurdo de que, mientras las Corporaciones demandadas no pueden interponer excepciones dilatorias, sin embargo cuando ellas recurren frente a sus propios acuerdos, los administrados demandados podrían ejercer excepciones dilatorias.

\section{La gratuidad.}

Otra interesante cuestión es la que hace referencia a la gratuidad en el recurso de lesividad objetivo. En relación con el recurso 
subjetivo de lesividad, la Jurisprudencia se venía mostrando contraria a la gratuidad, aun cuando un auto haya sentado doctrina contraria. Se entendía que el artículo 226 de la Ley municipal de 1935 al establecer que el procedimiento será gratuito para todos los que en ellos intervengan, se refiere tan solo a los recursos interpuestos con arreglo a la Ley municipal. Entendía la Jurisprudencia que el recurso de lesividad no es de los comprendidos ni en el Estatuto ni en la legislación municipal, sino que se trata sencillamente de la acción establecida en los artículos 2 y 7 y artículo 15 de la Ley de 1894.

Tal argumentación no tiene eficacia en nuestro caso puesto que el recurso de lesividad de la Ley de 1894 no es objetivo y, por tanto, la base de la acción está en el ordenamiento local, concretamente en el artículo 391 de la Ley de Régimen local recogido posteriormente en el artículo $2 .^{\circ}$ del texto refundido de la Jurisdicción contenciosa. Nuestra tesis es partidaria de la gratuidad en cuanto que el artículo 97 del texto refundido de lo contencioso de 8 de febrero de 1952 señala que el procedimiento administrativo en materia local será gratuito para todos cuantos intervengan en él. Como el procedimiento objetivo de lesividad hace referencia a materia local, concluimos afirmando la gratuidad del proceso que las Corporaciones locales interponen contra sus propios acuerdos cuando, siendo declaratorios de derechos, son ilegales y lesionan intereses económicos y directos de las mismas.

El plazo.

Una cuestión que of recía dudas era la referente al plazo para recurrir en vía de lesividad las Corporaciones locales. Se argumentaba que al no prevenir tal recurso la legislación local thabía que ir al derecho supletorio que señalaba el de tres meses contados a partir de la declaración de lesividad. Se afirmaba que el plazo que señalaba la legislación local era aplicable tan sólo al supuesto de que el recurrente fuera un administrado.

Esta era la doctrina que, como dominante, prevalecía en la práctica, habida cuenta que fué reforzada por la Circular del Tri- 
bunal Supremo de 27 de enero de 1931 al consagrar que el plazo de interposición del recurso contra acuerdos declarados lesivos era el de tres meses que señalaba el artículo $7 .^{\circ}$ de la Ley de lo Contencioso, y no el de un mes que señalaba el Estatuto municipal.

Tal doctrina fué por nosotros criticada en cuanto que suponía una indebida aplicación del ordenamiento supletorio a la legislación local, ya que el espíritu de ésta era reducir los plazos del procedimiento contencioso. Por otra parte, la acción objetiva de lesividad no era de las reguladas en la Ley de lo Contencioso de 1894. Además, si en ésta se daba para el recurso de lesividad el plazo de tres meses era porque también es de tres meses el plazo que para recurrir tenian los particulares frente a la Administración central, cosa que no ocurría en el ordenamiento local, en el que el plazo es mucho más breve.

La doctrina del plazo de los tres meses en el recurso de lesividad objetivo de las Corporaciones locales es ya precepto expreso en nuestro Derecho positivo, puesto que el texto refundido de la Ley de lo Contencioso de 8 de febrero de 1952 así lo consigna expresamente en su artículo $7 .^{\circ}$. Solución ésta que tal vez suponga una excesiva primacía para la Administración en cuanto por una parte cuenta con un plazo superior al que generalmente cuentan los particulares para recurrir contra los acuerdos de las Corporaciones locales, y por otra, cuenta con el dilatado plazo de los cuatro años para declarar la lesividad, con el que lógicamente no cuentan los administrados. Tal solución, a nuestro juicio, va en contra también de una de las necesidades más sentidas en nuestra justicia administrativa: la brevedad del procedimiento.

\section{Manuel Francisco Clavero Arévalo \\ Catedrático de Derecho Administrativo do la Universidad de Salamanca}

